\title{
Raising risk preparedness by flood risk communication
}

\author{
E. Maidl and M. Buchecker \\ Swiss Federal Research Institute WSL, Unit Economy and Social Sciences, Birmensdorf, Switzerland \\ Correspondence to: E. Maidl (elisabeth.maidl@wsl.ch)
}

Received: 18 October 2013 - Published in Nat. Hazards Earth Syst. Sci. Discuss.: 10 January 2014

Revised: 28 May 2015 - Accepted: 6 June 2015 - Published: 18 July 2015

\begin{abstract}
During the last decade, most European countries have produced hazard maps of natural hazards, but little is known about how to communicate these maps most efficiently to the public. In October 2011, Zurich's local authorities informed owners of buildings located in the urban flood hazard zone about potential flood damage, the probability of flood events and protection measures. The campaign was based on the assumptions that informing citizens increases their risk awareness and that citizens who are aware of risks are more likely to undertake actions to protect themselves and their property.

This study is intended as a contribution to better understand the factors that influence flood risk preparedness, with a special focus on the effects of such a one-way risk communication strategy. We conducted a standardized mail survey of 1500 property owners in the hazard zones in Zurich (response rate main survey: $34 \%$ ). The questionnaire included items to measure respondents' risk awareness, risk preparedness, flood experience, information-seeking behaviour, knowledge about flood risk, evaluation of the information material, risk acceptance, attachment to the property and trust in local authorities. Data about the type of property and sociodemographic variables were also collected.

Multivariate data analysis revealed that the average level of risk awareness and preparedness was low, but the results confirmed that the campaign had a statistically significant effect on the level of preparedness. The main influencing factors on the intention to prepare for a flood were the extent to which respondents evaluated the information material positively as well as their risk awareness. Respondents who had never taken any previous interest in floods were less likely to read the material. For future campaigns, we therefore recommend repeated communication that is tailored to the information needs of the target population.
\end{abstract}

\section{Introduction: risk communication}

During the last decade, several valuable tools for visualizing natural hazards and flood risk information, such as hazard maps, have been developed and implemented in an increasing number of countries (de Moel et al., 2009). This development was promoted by the 2007 European Flood Directive and mirrors a new paradigm of integrated risk management. In this integrated approach, hazard maps not only provide information to natural hazard experts and city planners, but can also be made available for the public, which requires informing the public about the availability of such maps. There is a shift in risk management away from the traditional danger-based approach, towards a new integrated approach that treats inhabitants of risk areas and property owners as responsible actors in risk management. The new paradigm is about establishing a culture of risk that involves various actors including stakeholders, experts, authorities and the population in areas at risk. Therefore, a successful implementation of integrated risk management strategies requires an understanding and consideration of social factors that influence the interaction between these actors (Bradford et al., 2012; Renn, 2008). The availability of technically elaborated risk assessment tools for experts, and the building of protective structures, certainly improves hazard protection but, in terms of disaster risk reduction, the effect of such structural measures is limited. For instance, these measures encourage an illusion of safety known as the levee effect (Tobin, 1995; Demeritt et al., 2011). Effective flood risk management should additionally focus on strengthening social capacities such as risk awareness and a sense of self-responsibility in the affected population. Risk managers in municipalities, civil protection and insurance agencies are therefore concerned with raising people's awareness of risk and in particular their preparedness. Inhabitants of risk areas, and especially property 
owners, need to be aware of their role as responsible actors in risk management.

The communication of risk-related information has become an important element in risk governance that concerns various stakeholders (Renn, 2008). Despite the broad consensus on the importance of raising public awareness by effective communication (Burningham et al., 2008; Krasovskaia et al., 2007), little research has been done on the effects of particular risk communication strategies (Höppner et al., 2012). The emphasis has been on communication formats rather than strategies. The literature on risk communication suggests that two-way communication is more efficient than one-way communication, but two-way communication limits the extent to which the wider public can be reached because many people are not prepared to attend information meetings or workshops (Höppner et al., 2008; Junker et al., 2007). As a result of such limitations, one-way strategies are still common in practice; so it is important to understand the possible effect of such campaigns.

Experts and laypeople tend to perceive risks in different ways and tend to use different terms to discuss them (Veland and Aven, 2013). Risk experts translated knowledge into hazard maps: a visual state-of-the-art tool to explain important information about what it means to live in a flood risk area (Basic et al., 2009). People have been found to show a great variety in how they respond to such information (Lindell and Perry, 2004). The first aim of risk communication is to reach the attention of the highest possible number of people at risk and make them aware of the availability of the hazard maps. They then need to be convinced that floods are relevant to their lives, and to be motivated to implement protection measures. Knowing how people respond to such communication, therefore, is important to assess the value of hazard maps as a means of communication. Siegrist and Gutscher (2006) found that people living in Swiss Alpine regions are well aware of the risks, whereas those living in regions that are seldom affected were hardly aware of the risks. In this study, we seek to find out the extent to which one-way communication can increase risk awareness and risk preparedness, how risk awareness and risk preparedness interact, and which other factors influence risk preparedness. We aim to contribute to a better understanding of individual and contextual conditions that will allow the tailoring of risk communication to specific circumstances. For the sake of clarity, we have reformulated the aims into two specific research questions: (1) to what extent can one-way risk communication improve flood preparedness? And (2) what other factors influence the level of flood preparedness?

To address these aims, we examined the effects of a risk communication strategy used in the city of Zurich in which hazard maps (see Fig. 1) were made available to transfer expert knowledge to the laypeople living in areas at risk to encourage them to prepare for a flood event. In particular, we explore the effects of a communication campaign on property owners' flood risk preparedness in an urban context that is at

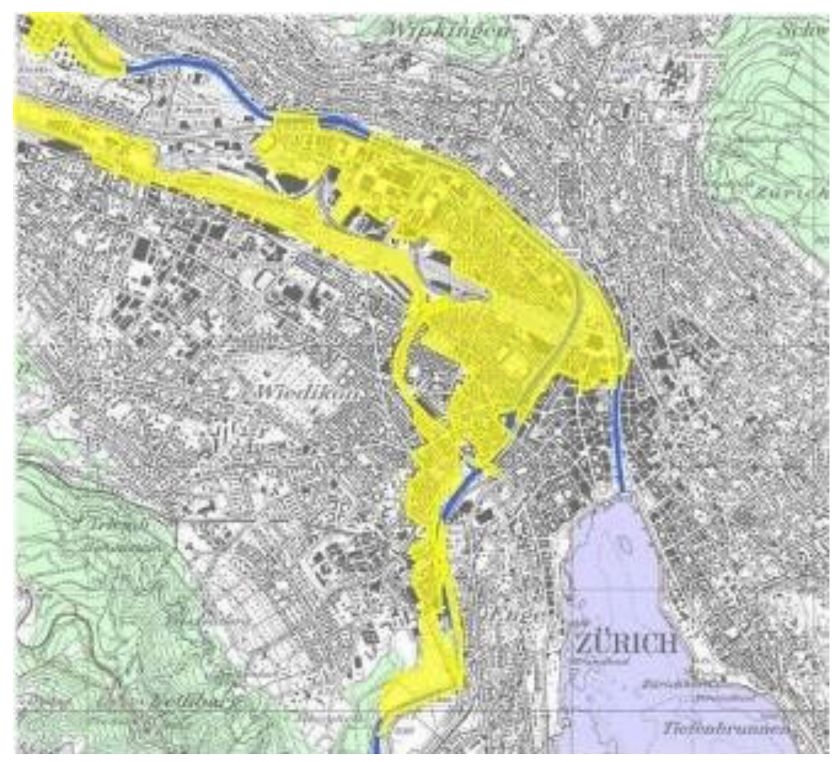

Figure 1. Hazard map of the city of Zurich $\left(^{(}\right.$WWEA: Office of Waste, Water, Energy and Air, Canton of Zurich).

risk of floods but where the floods occur only seldomly with a potential for great damage. The study should contribute to a better understanding of the influence of one-way strategies; as is commonly applied in practice, on risk preparedness and awareness.

\section{Relevant findings and open research questions on risk preparedness and risk communication}

Social aspects have been generally recognized in risk research as key components of risk management. The recognition of social determinants of people's response to natural hazards goes back to Gilbert White's work in the 1940s. Since then, the emergence of empirical studies following the psychometric approach (Slovic, 1987; Fischhoff, 1995) has paved the way for further developments in empirical research on the individual perception of risks. Other studies have pointed out that risk perception rather depended on the cultural context (Douglas and Wildavsky, 1982; Kahan et al., 2011). In the following years, researchers developed new theoretical approaches based on those previous insights. This has resulted in more sophisticated models such as protection motivation theory (Rogers and Prentice-Dunn, 1997; Floyd et al., 2000; Grothmann and Reusswig, 2006), which distinguishes between coping appraisal and threat appraisal to explain people's responses to floods and mitigation behaviour. Although research provides valuable theoretical frames to which empirical findings can be linked, basic questions on the potential effect of communication on risk awareness and preparedness are still open. In the large body of literature on 
risk preparedness and its influencing factors, there is little attention given to dependent risk communication variables.

There are few empirical studies on the effects of risk communication, although the need for further research is frequently pointed out (Kellens et al., 2013; Bubeck et al., 2012). Many of the studies reviewed by Kellens et al. (2013) and Bubeck et al. (2012) focused on predictors of risk preparedness or on the effect of communication on awareness, but few addressed the effect of communication on preparedness. The variety of different research questions and measurement approaches makes it difficult to compare results and draw conclusions on effective communication strategies. Although risk awareness is often presumed to be a precondition of risk preparedness, the extent to which that is actually the case is especially not clear. However, several factors have been found to be relevant for risk preparedness and risk awareness.

Most studies on risk awareness have shown that survey participants are seldom concerned about natural hazards, and their level of preparedness appears to be correspondingly low (Botzen et al., 2009a; Bubeck et al., 2013; Birkholz et al., 2014; Terpstra et al., 2009; Siegrist and Gutscher, 2006; Siegrist, 2013; Thieken et al., 2007; Wachinger et al., 2013; Wagner, 2007). This supports the assumption that there is a relationship between risk awareness and mitigation behaviour. However, empirical evidence on the relationship between risk awareness and hazard preparedness is ambiguous. Some studies suggest a significant correlation (Lindell and Perry, 2000; Lin et al., 2008), but others question whether there is a linear relationship between awareness and behaviour (Scolobig et al., 2012). They rather conclude that other influences might be more important so there can be no general strategy for raising awareness and motivating people to take action. Scolobig et al. (2012) recommend caution in interpreting positive correlations between awareness and preparedness, because the relationships between perceptions, attitudes, and cultural or political context factors are rather complex; and the nature of risk is also complex. This indicates that risk awareness is a multi-dimensional concept that needs to be studied in a more differentiated way using explorative methods (Miceli et al., 2008). A reasonable conclusion is that the existing results do suggest that risk awareness determines preparedness to some extent, but the correlations tend to be rather weak (Bubeck et al., 2012).

In the discourse on risk preparedness, some authors emphasize the importance of the cultural context (Ge et al., 2011), while others rather point out the influence of the personal characteristics, such as personal interest in the topic or prior knowledge (Thieken et al., 2007; Hagemeier-Klose et al., 2009) of the individuals who receive risk communication. Furthermore, the role of emotions (Terpstra, 2011; Slovic, 2010) and trust in public risk management (Löfstedt and Perri, 2008; Lin et al., 2008) has been found to be important. However, the role of knowledge needs to be especially clarified, since the aim of risk communication is to increase knowledge about hazards. The ambiguity of results on the topic is thought to be a consequence of using different measurement methods and theoretical frameworks.

Although research is embedded in different theoretical paradigms, there are some factors that seem to generally influence risk preparedness. Considering the complex interplay of different influencing factors, it is important to identify such general influences in order to provide practical recommendations for risk managers. Most studies on protective behaviour confirm that people who have experienced floods are more likely to prepare for a future event (e.g. Siegrist and Gutscher, 2008). Nevertheless, the role of experience as a predictor of protective behaviour is not straightforward (Takao et al., 2004; Thieken et al., 2007). Recent studies have found that experience tends to be rather mediated by beliefs about the effectiveness of protective measures (Zaalberg et al., 2009), by the negative emotions that may be associated with the flood experience (Harries, 2012) and how far back in time the flood experience took place. Interestingly, Terpstra (2011) showed that the impact of past experience on individuals lasts longer if the consequences of a severe event are anchored in the public mind. A review of results on hazard experience as an important predictor of preparedness leads us to the conclusion that we need to pay attention to the quality of experience and emotions that such experience had caused. Correspondingly, empirical findings show that rational action and factual knowledge have limited power to explain protective behaviour. Research within the heuristics paradigm especially highlights that individuals seldom make decisions based on reflecting on all possible facts and outcomes (Keller et al., 2006; Slovic et al., 2004).

Since the significance of social and psychological determinants is increasingly recognized in risk management, recommendations for risk communication focus on participative and dialogue-based approaches that aim to involve stakeholders and the public as responsible actors. As Demeritt et al. (2011) pointed out, early approaches were based on the assumption that a layperson's risk awareness and behaviour depend merely on what information is available and how correct it is. According to this deficit model, providing appropriate information is enough to ensure adequate response to floods. This rationale is still common in risk communication. In a review of risk communication strategies in Europe, Höppner et al. (2012) revealed a gap between practice, which tends to follow traditional approaches, and recent research, which recommends two-way communication and more deliberative approaches tailored to the needs of the population (Renn, 2008; Martens et al., 2009). However, the effort required by dialogue-based strategies often seems very high to practitioners. The deficit model still seems to be predominant in the practice of risk management, and there has been little study on the effects of dialogue-based communication. One study that particularly focused on the effect of two-way communication on property owners' perception of flood risks found only limited changes in the respondents' 
perceptions (Terpstra et al., 2009). The communication strategy in the study by Terpstra et al. (2009) involved deliberative elements, such as workshops and focus groups, in which participants could express their views and discuss them with others. The results showed only a weakly significant influence on risk perception and the way it was conceptualized.

Although risk communication is assumed to strengthen resilience and mitigate flood damage, the number of empirical studies on the effect of risk communication strategies on people's behaviour is still limited. According to Lindell and Perry (2004), risk communication is a necessary substitute for personal experience in areas at risk that are seldom affected by hazards. Effective risk communication therefore needs to evoke underlying beliefs, touch people's attitudes, and address their self-responsibility (Slovic et al., 2004; Keller et al., 2006; Zaalberg et al., 2009; Terpstra, 2011; Visschers et al., 2012). The population needs to be aware of risks and provided with knowledge about how to prepare. The crucial question is how to get the attention of people who have not been affected by the topic so far. In this respect, the role of pictures and emotions is discussed. In particular, "worry" was identified as an important factor to explain whether people inform themselves about risks and become motivated to prepare for an event (Raaijmakers et al., 2008; Miceli et al., 2008). The importance of understanding emotions was also highlighted in a comparative empirical study on communication strategies focusing on residents' responses to flood warnings in four European countries (O'Sullivan et al., 2012). In line with the findings of Höppner et al. (2012), they found that one-way risk communication had limited effects, because it failed to address the multi-dimensional determinants of people's behaviour, including attitudes and affect.

Even more basic for effective communication strategies is to consider the availability of information. Griffin et al. (2004), in a study on people's information-seeking behaviour, found that the accessibility of information, its comprehensiveness, and its perceived credibility determined the effectiveness of communication strategies. In their study they also found that the respondents' self-estimated information need could be predicted by the degree of worry and also by other peoples' expectations. This result strengthens the view that attitudes towards risks are not just a matter of factual knowledge. Therefore, the potential effect of communication strategies depends on how people in areas at risk perceive available information. Although subjective perceptions and attitudes clearly affect risk preparedness, Thieken et al. (2007) showed that providing factual knowledge does raise awareness and improve preparedness. However, not all empirical studies have found a positive correlation between knowledge and awareness and the motivation to take action (Bubeck et al., 2012).

The review of existing literature shows that predictors of preparedness influences on effective communication are overarching. This is also true for further important factors, i.e. responsibility and trust. Apart from experience and emotions, the perceived responsibility of authorities was also found to influence individual risk preparedness in several studies (Botzen et al., 2009a; O'Sullivan et al., 2012; Eiser et al., 2012) although Terpstra et al. (2006) found no such correlation. Their results indicate that the influence of perceived responsibility on preparedness is a matter of citizens' trust in their government, and the degree to which citizens trust governments varies according to political and cultural circumstances. Strong reliance on public authorities may weaken individual motivation to take action but it may make it more likely that the target population will take information provided seriously. There is strong agreement with the view that risk communication is a means of increasing preparedness (Botzen et al., 2009a; Höppner et al., 2012) and previous studies provide insights into the factors that can influence mitigation behaviour, but findings are often ambiguous, and so general conclusions about the effect of risk communication on hazard preparedness cannot yet be drawn. Clarification is required on the extent to which risk awareness and other influences such as knowledge, emotions, or personal experience influence an individual's decision to take protective actions or not. Furthermore, primary research is needed to determine under which conditions risk communication is recognized and will lead to appropriate steps being taken by the target population.

\section{Methods}

\subsection{Study area}

Switzerland is a country frequently affected by natural hazards. Nationwide hazard maps (see Fig. 1) combining information about the likelihood and the extent of a hazard event are available and municipalities are obliged to take these into account in city planning and constructional design. They should also inform property owners about the flood risk in the area and any compulsory or voluntary protective measures the hazard map involves. Zurich was among the first municipalities to develop a master plan for the implementation of the hazard maps in an urban area in Switzerland. To realize this master plan, a coordination committee was established including experts from several departments and organizations who were involved in relevant city planning, emergency management and environmental protection. Among the tasks of this committee was the organization of an information campaign on the flood hazard risk in the city of Zurich. Raising property owners awareness of flood risks was challenging, because the last severe flood in Zurich occurred 100 years ago and therefore is not anchored in the public mind. In this campaign, letters were sent out to all property owners with property in hazard zones where a HQ100 flood might occur. With these letters the owners were informed that their property was located in a flood risk zone. The letters 
also contained information on possible damages, protection measures, past flood events, legal implications, information how to act in case of an emergency and instructions how to get further information. In the cover letter, they were furthermore encouraged to use a link for accessing the online available hazard map. The use of the online information was a crucial element of the information campaign, because it was the only way for the property owners to find out in which hazard area their property was located. Only with this information could they understand which personal implications the hazard map had for them. Only with this information they could understand which personal implications the hazard map had for them. In the red and blue hazard areas those constructing new buildings must comply with specific legal regulations. In the red and blue hazard areas those constructing new buildings must comply with specific legal regulations. Property owners in the yellow and yellow-white areas need to inform the authorities whether they intend to take mitigation measures. They were not only informed about appropriate structural and temporary measures, but also about what to do in the case of an emergency. The coordinator of the master plan committee wished to receive information about the success of the information campaign. He was in the same period involved in the participatory planning of a regional flood protection project that we were evaluating within the EU project KULTURisk (Buchecker et al., 2013), and so he contacted us with the suggestion to evaluate their information campaign within the same project.

\subsection{Instrument and sample}

We evaluated the information campaign using a standardized survey. As we were contacted only a few weeks before the information campaign took place, conducting an evaluation based on repeated measurement was not an available option. A further contextual condition for our evaluation study was given by the design of the information campaign, namely that all the property owners affected by the hazard map of the city of Zurich were involved, so that it was not an option to establish a proper control group. We therefore decided to conduct a cross-sectional survey to evaluate the information campaign.

We included items suitable to compare different respondent groups. For this purpose we measured the intensity with which the property owners had studied the information material. This design should allow us to measure the success of the campaign by considering the effect of the individual exposure to the intervention on the intended outcomes. An advantage of this design was that all respondents had some basic knowledge of the issue, so that the potential readiness to answer a quite comprehensive questionnaire could be expected to be rather high. This offered the opportunity to collect a diversity of indications about the success of the information campaign, which contributed to a high validity of the findings.
Originally, the survey was envisioned to take place 2 months after the property owners had received the information letters from the municipality, but the delivery had to be delayed by 2 months due to political concerns. Since the period of time between the campaign and our evaluation study was still only 4 months, we assume that any measures had been implemented at the time of data collection were already in existence before the campaign. Implementing such measures requires sound considerations and consultancy.

The standardized questionnaire was developed based on existing literature on the issue. It comprised 34 questions with a total of 108 single items on 8 pages. After conducting a pretest (162 questionnaires), it was administered in February 2012 to a randomly selected sample of 1338 persons from the target population of 10500 affected property owners of the city of Zurich, which was structured according to the three hazard areas (500 persons per blue, yellow and yellow-white area). The response rate was $34 \%$, amounting to 460 returned questionnaires. The response rate was highest in the risk blue zone (37\%), and lowest in the yellowwhite zone $(28 \%)$. A comparison with data from population census about property ownership showed that the data set is representative of property owners in Zurich with respect to age and type of ownership (private, condominium ${ }^{1}$, or organization). Regarding the level of education and gender, welleducated males were over-represented in comparison to the overall population in Zurich.

\subsection{Operationalization of the key concepts}

Due to the lacking coherence, studies differ a lot in what is actually measured. Addressing our research questions, (1) to what extent one-way risk communication can improve flood preparedness and (2) what other factors influence the level of flood preparedness, we first want to clarify our approach: in the following, we use the term "preparedness" as the intention to implement private flood protection measures in the future. From this, we distinguish the term "current preparedness" for protection measures that have already been implemented by the time of the survey. Further, we provide a full overview of items in our questionnaire to make transparent to the reader how we conceptualized and developed our dependent variable, which may help future researchers to choose relevant items in their own study context. The items used in the questionnaire are not only limited to items covering risk preparedness and awareness. No general agreement on standardized measures has been developed and the operationalization of key concepts in hazard risk research such as risk preparedness and awareness is not coherent (Bubeck et al., 2012). We claim that it is important to design questionnaires that also include items on political culture and the respondents' relation to their living environment. Bubeck et al. (2012) suggest that a common way to operationalize

\footnotetext{
${ }^{1}$ Private co-ownership
} 
risk awareness is to measure the perceived probability of an event or its consequences (Thieken et al., 2007; Siegrist and Gutscher, 2006; Takao et al., 2004; Miceli et al., 2008; Lindell and Hwang, 2008). Other researchers apply combined measures of probability and consequences (Grothmann and Reusswig, 2006). Flood preparedness is either measured as the intention to implement protective measures, or in terms of already adopted protection measures. Information-seeking behaviour is also often regarded as a dimension of protective behaviour. Researchers differ not only in how they operationalize key concepts, but also in the level of measurement. In some studies only one dimension, for instance, the response in case of an emergency, is applied to measure risk preparedness, while others use multi-dimensional scales based on several items. In this study, we chose question items and wording similar to those used in previous surveys on the perception and communication of risks (Zwick and Renn, 2002; Martens and Ramm, 2008) as far as they were applicable in the context of our study, and supplemented them with questions related to the information campaign.

We operationalized the dependent variable "flood risk preparedness" as a set of six particular protection measures described in the information campaign. As the survey was cross-sectional, we measured the level of preparedness as the willingness to implement these measures in the future. Respondents could answer on a 5-point Likert-scale from "definitely no" coded " 1 " to "definitely yes" coded " 5 ". An "already implemented" option was included and coded " 6 ". Using this information we constructed a variable to measure the current state of preparedness separately. The distinction between already adopted measures and future preparedness is necessary to evaluate the effect of the campaign.

Risk awareness was operationalized as a set of items measured on 4-6-point Likert-scales, including emotional aspects. It consists of the two subscales "risk perception" and "relevance of the topic" (see Table 1). Our decision to combine these subscales into one overarching scale and take it as our dependent variable is based on careful comparison of separate regressions on both subscales (which are not included in this paper). We found this approach beneficial in terms of a clear interpretation of the independent variables. Nevertheless, the benefit of a clear interpretation is at the expense of some details that were revealed in the separate analysis. For instance, we found that some variables were significant predictors of only one subscale, but not the other: knowledge before the campaign as well as perceived responsibility of politicians only influenced the relevance of the topic, but not risk perception. On the other hand, risk perception was influenced by personal experience, which was not a significant predictor of the relevance subscale. It is important to keep in mind that the emotional component of being worried about floods is included in our overarching risk awareness scale. The item "worry" itself is a component of the risk perception subscale (see Table 1).
To measure people's knowledge, we distinguished between subjective knowledge and objectively measurable knowledge about flood risk. Subjective knowledge was operationalized as people's self-assessed knowledge before the campaign and at the time of the survey, and objective knowledge about their location in a risk area in comparison with its actual location. This comparison was also treated as an additional indicator of risk awareness.

In addition to risk awareness and preparedness, items were included to collect data on the following: the information campaign and its evaluation, respondents' attitudes to other risks (fire, industrial accidents, ozone in the air and nuclear power plants), evaluation of the public discourse on these kinds of risks, general risk aversion, the priority of safety over other values (e.g. avoidance of public debt or regulation), personal flood experience and flood experience of acquaintances, risk acceptance, attitudes towards authorities (trust, responsibility), type of property, attachment to the property, and socio-demographic data including a background in dealing with natural hazards as professionals or volunteers (see Tables 1 and A1).

\section{Results}

\subsection{Risk perceptions}

Table 1 provides an overview of the characteristics of all of the scales we constructed and used for further analysis. Table A1 lists item characteristics of single variables that were not used for scale construction, e.g. the variable "intensity of studying the material". The overview comprises all items asked in the questionnaire, including descriptive measures of central tendency and standard deviations. The analysis revealed that property owners in Zurich generally felt little concern about flood risks (see Table 1) according to the responses to all risk awareness items included in the questionnaire. These items include both the perceived probability of a flood and the emotional aspect of being worried about the flood risk.

A vast majority of $(82.8 \%)$ of the respondents regarded the flood risk in the area where their property is located as either "rather low" or "low", while $15.4 \%$ reported that the risk was "high" or "rather high". This is $7 \%$ less than the proportion of respondents who perceived the flood risk for the city as high or rather high. Only $11.0 \%$ of the property owners in the sample "agreed" or "rather agreed" with the statement "I am worried about flood risks". Interestingly, respondents who assumed the flood risk to be high seemed to be generally cautious people as they also regarded the risks of fire and industrial accidents as high and thought that the risks associated with nuclear energy or genetic engineering were rather underestimated in the media. These findings suggest that individual risk awareness is partly rooted in personal attitudes towards risk. The proportion of respondents who 
Table 1. Scale descriptives.

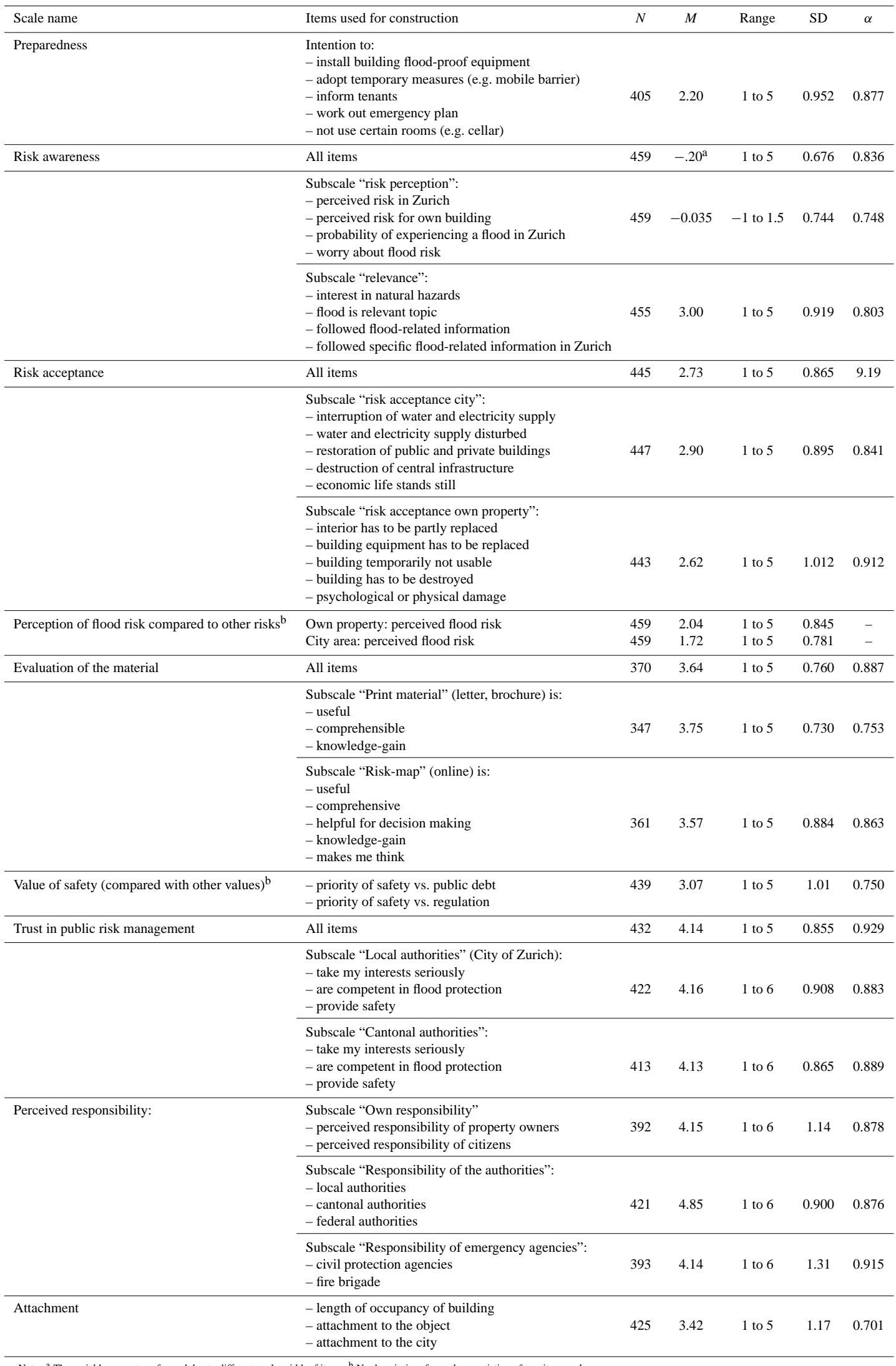

Notes: ${ }^{a}$ The variable was $z$-transformed due to different scale-width of items. ${ }^{b}$ No descriptives for scales consisting of two items only 
Table 2. Bivariate correlations of flood risk preparedness with other variables.

\begin{tabular}{|c|c|c|}
\hline Variable & $r^{\mathbf{a}}$ & $n$ \\
\hline Evaluation - subscale hazard map ${ }^{\mathrm{b}}$ & $0.319 * * *$ & 361 \\
\hline Risk awareness - subscale perception ${ }^{b}$ & $0.318 * * *$ & 459 \\
\hline Risk awareness - subscale relevance $\mathrm{e}^{\mathrm{b}}$ & $0.278 * * *$ & 455 \\
\hline Information need & $0.308 * * *$ & 445 \\
\hline Readiness to seek flood-related information in different media ${ }^{b}$ & $0.276^{* * *}$ & 434 \\
\hline Reason not to implement measures: cost-benefit & $-0.267 * * *$ & 460 \\
\hline Number of reasons not to implement measures & $-0.222 * * *$ & 460 \\
\hline Evaluation - subscale mail information ${ }^{\mathrm{b}}$ & $0.245^{* * *}$ & 347 \\
\hline Gender $($ female $=1$, male $=2)$ & $-0.214 * * *$ & 445 \\
\hline Preference to invent in flood protection (against keeping public debt $\&$ regulation low) & $0.203 * * *$ & 439 \\
\hline Perceived responsibility politics & $0.181 * * *$ & 421 \\
\hline General intention to renovate property & $0.178 * * *$ & 448 \\
\hline Self-assessed ability to prevent flood damage & $0.177 * *$ & 445 \\
\hline Perceived risk of house fire & $0.164 * *$ & 459 \\
\hline Perceived risk of industrial accident & $0.163 * *$ & 457 \\
\hline Intensity of attention paid to the information material & $0.162 * *$ & 450 \\
\hline Perceived responsibility of civil protection organizations & $0.163 * *$ & 393 \\
\hline Perceived responsibility of other actors & $0.574 * *$ & 28 \\
\hline Perceived under-estimation of flood risks in public discourse & $0.156^{* *}$ & 427 \\
\hline Perceived responsibility of insurance companies & $0.153 * *$ & 401 \\
\hline Would access special website for hazard information & $0.140^{*}$ & 441 \\
\hline Perceived under-estimation of nuclear energy in public discourse & $0.140 *$ & 435 \\
\hline Professional or voluntary background related to natural hazards & $0.138^{*}$ & 460 \\
\hline Talked to nobody about flood & $-0.135^{*}$ & 460 \\
\hline Owner of a house & $-0.132 *$ & 264 \\
\hline Assumption that flood damage will increase in future & $0.116^{*}$ & 455 \\
\hline Length of time spent on consulting the online hazard map & $-0.115^{*}$ & 451 \\
\hline Talked about floods with friends and acquaintances & $0.111 *$ & 460 \\
\hline Highest level of education: university & $-0.108^{*}$ & 460 \\
\hline Priority of flood protection vs. public green space & $0.109 *$ & 432 \\
\hline Property use: live there & $-0.102 *$ & 460 \\
\hline General risk-aversion & $0.101 *$ & 448 \\
\hline Trust in authorities & $0.100(p=0.054)$ & 432 \\
\hline Owner of business offices & $0.098(p=0.055)$ & 63 \\
\hline Perceived risk area $(1=$ low risk, $2=$ medium risk, $3=$ high risk $)$ & $0.110(p 0.056)$ & 350 \\
\hline
\end{tabular}

perceived risk of a flood as "rather high" or "high" (15.4\%) was similar to the proportion who reported the same rating to other risks such as house fire $(15.0 \%)$ or industrial accidents $(20.6 \%)$. Although the flood risk tended to be rather underestimated, a detailed look at the individual "relevance" items (see Table 1) showed that the majority (68.7\%) of the respondents were at least rather interested in natural hazards, and that flooding was a relevant topic for $39.2 \%$. At least $13 \%$ of the respondents had sought specific information on flood risks generally, and $23.6 \%$ had obtained specific information on the situation in Zurich.

Respondents with a high level of awareness were more willing to collect information using different media (see Table 2, bivariate correlations). The self-reported level of preparedness corresponded with the generally low level of flood risk awareness. The majority of the respondents had not, or had hardly, considered implementing the protective measures described in the information material. For instance, $47.7 \%$ of the respondents said they were unlikely, responding with "probably not" or "definitely not", to install technical building equipment, such as heating, in a flood-proof way, while $13.0 \%$ were undecided and $14.4 \%$ responded with "probably yes" or "definitely yes" that they were willing to implement this in the future. A further $11.1 \%$ had already installed flood-proof equipment. The mean intention to implement flood-protection measures sometime in the future was $16 \%$. In comparison, $43.0 \%$ of the property owners reported 
they were willing to carry out general restoration ${ }^{2}$ not specifically related to flood protection. Correspondingly, most of the $41.0 \%$ of property owners who already implemented one or several measures had implemented general restoration measures.

Analysis of the reported risk acceptance revealed a certain discrepancy between willingness to prepare for a flood and willingness to accept potential damage. Possible damage caused by a HQ100 flood appeared to be acceptable to the respondents, especially concerning damage to the area where they own property (Table 1). On the other hand, respondents tended to prefer to bear the consequences of a flood rather than investing in prevention measures (Table A1), even if they reported having the capacity to implement such measures $^{3}$. In terms of general risk aversion, the results show that the respondents have a rather positive attitude towards risks (Table A1).

The internal consistency of the risk awareness scale decreases when the worry item is not included, which shows that risk awareness is not just a product of probability estimation and interest in the topic, but is closely related to emotions. This is the only result in which experience was found to be a significant factor. Furthermore, we found that high (selfreported) knowledge about floods before the campaign was a significant predictor of relevance (stand. $\beta: 0.043, p=0.004$, $n=286$ ), but did not contribute to the variance of the perception scale. All other independent variables influenced both outcome variables in a very similar way except that older respondents showed less risk awareness than younger people. Age was found to be negatively correlated with the strength of opinion that floods are of personal relevance.

\subsection{Experience, knowledge and information behaviour}

Property owners' knowledge about floods was found to be primarily based on information received through the media and public information. In response to the included questions on preferred information media, we found that printed information, such as newspapers $(83.6 \%)$ or information letters $(83.2 \%)$, were used more than the internet, TV or radio, each less than $80 \%$. Few of the respondents reported having had a personal experience with flood events. The majority (79.1\%) had never been affected by flood, $12.8 \%$ had been affected once and only $6.3 \%$ of the respondents had experienced several flood events. Respondents with a professional or volunteer background in the field of natural hazards, such as members of local fire brigades or civil protection agencies, made up $11 \%$ of the sample. We found that respondents with a professional/volunteer background had an especially high

\footnotetext{
${ }^{2} \mathrm{~A}$ general restoration of a building cannot be treated as a particular flood protection measure, even if it contributes to mitigation, as the intention is not to prepare for a flood.

${ }^{3}$ There was no significant statistical relation between the selfassessed ability to implement measures and preference to invest in safety.
}

knowledge and awareness of flood risks, and had more often already adopted protection measures. The information campaign was reasonably well received across the whole sample with approximately two-thirds reporting that they had studied the brochures, but only a third reporting that they had used the online information. Elderly respondents were significantly more reluctant to use the internet for finding further information $(r(n=322)=-0.261, p<0.001)$.

The proportion of property owners who could correctly nominate their own risk area was astonishingly low (17.4\%), with many $(27.4 \%)$ underestimating the risk level or conceding that they did not know which risk area applied to their property $(26.1 \%)$. Nearly a quarter $(23.9 \%)$ did not answer this factual knowledge question. In contrast, $44.1 \%$ agreed or rather agreed with the statement on the selfassessed knowledge that "I am well informed about the flood risk in Zurich". When asked to assess their knowledge before the information campaign, only $14.6 \%$ thought it was "good" or "rather good". This result shows that the information campaign increased the respondents' self-assessments of their own knowledge, even if they had felt that they were well informed beforehand. Correspondingly, most respondents reported a knowledge gain as a result of reading the information brochures or accessing the online information. Only $16.6 \%$ reported that the material did not increase their knowledge about flood risks. High interest in the topic of floods correlated with a high information need $(r(n=441)=0.373, p<0.001)$ as well as high subjective (self-assessed) knowledge $(r(n=449)=0.368, p<0.001)$. However, factual knowledge about the location in a risk zone did not correlate significantly with the degree of interest.

A comprehensive list of all variables that significantly correlated with risk preparedness is provided in Table 2 and shows that the decision to prevent flood damages is rooted in a variety of factors. The main influences are related to individual perceptions, attitudes and variables that refer to information seeking. Furthermore, how a person uses their property and how long they have lived there are significantly correlated with emotional attachment to the property. Regarding the question on how much one-way communication can influence risk awareness, the variables on information behaviour correlated relatively strongly with preparedness. Respondents who were willing to implement measures expressed a greater need for further information than those who did not consider taking any action, and they were also prepared to seek information using different media. Focusing on the campaign in Zurich, those respondents who studied the information material intensively showed a high level of preparedness, but there was only a low correlation between preparedness and the amount of time dedicated to the online material (see Table 2).

Another relevant result for risk communication is that neither the level of self-assessed knowledge about floods nor personal flood experience was related to the level of preparedness. For the interpretation of this result, it is impor- 
Table 3. Predictors of preparedness (future intention).

\begin{tabular}{lccr}
\hline & Model 1 & Model 2 & Model 3 \\
\hline & $R^{2}=0.244$, & $R^{2}=0.256$ & $R^{2}=0.269$, \\
& $F(6,320)=18.116$, & $F(6,317)=19.142$, & $F(7,309)=17.611$, \\
& $p<0.001$ & $p<0.001$ & $p<0.001$ \\
\hline Independent variables & Stand. $\beta(\mathrm{SE})$ & Stand. $\beta(\mathrm{SE})$ & Stand. $\beta(\mathrm{SE})$ \\
\hline Evaluation & $0.187^{* * *}(0.079)$ & $0.238^{* * *}(0.062)$ & $0.195^{* * *}(0.065)$ \\
Information need & excluded & $0.221^{* * *(0.046)}$ & $0.186^{* * *}(0.047)$ \\
Risk awareness & $0.186^{* *}(0.066)$ & excluded & $0.141^{*}(0.081)$ \\
Cost-benefit evaluation of & & & \\
protection measures & $-0.168^{* *}(0.094)$ & $-0.188^{* * *}(0.092)$ & $-0.164 * *(0.093)$ \\
Priority of security & $0.163^{* *}(0.050)$ & $0.148^{* *}(0.050)$ & $0.133^{* *}(0.049)$ \\
Gender & $-0.158^{* *}(0.097)$ & $-0.133^{*}(0.097)$ & $-0.135^{* *}(0.097)$ \\
Reconstruction intention & $0.167^{* *}(0.062)$ & $0.153(0.062)$ & $0.150^{* *}(0.061)$ \\
\hline
\end{tabular}

*** $p<0.001 ; * * p<0.010 ; * p<0.050$.

Table 4. Predictors of current state of preparedness (already adopted measures).

\begin{tabular}{ll}
\hline Model summary & $\begin{array}{l}\text { Dependent variable } \\
\text { Stand. } \beta(\mathrm{SE})\end{array}$ \\
\hline Independent variables & $\begin{array}{l}R^{2}=0.132, \\
F(6,392)=10.915, \\
p<0.001 .\end{array}$ \\
\hline Cost-benefit evaluation & $-0.200(0.88)^{* * *}$ \\
\hline Risk acceptance (evacuation) & $0.170(0.40)^{* * *}$ \\
\hline Self-assessed knowledge & $0.134(0.40)^{* *}$ \\
\hline Professional or voluntary \\
background in natural hazards & $0.131(1.38)^{* *}$ \\
\hline General risk aversion & $0.129(0.58)^{* *}$ \\
\hline Duration of residence & $0.092(0.27), p=0.075$ \\
\hline$* * * p<0.001 ; * *<0.010 ; * p<0.050$ \\
\hline
\end{tabular}

tant to know that the last severe flood in Zurich took place approximately 100 years ago.

\subsection{Predictors of preparedness}

Table 3 shows three regression models, with models 1 and 2 showing the influence of risk awareness on preparedness, and with model 3 including both significant predictors. All models confirmed that the campaign had a motivating effect on risk preparedness but this effect did not depend on whether the respondents had read the information material or not. Instead, the crucial factor was how intensively the respondents had studied the material. It influenced two of the most powerful predictors of preparedness, namely the evaluation of the material, and risk awareness (see Table 5). Considering the results of bivariate correlation, risk aware- ness was more strongly related to preparedness than information need. Since these predictors also relate to each other $(r(n=443)=0.409, p<0.001)$, we compared two regression models, using only one of the two variables (either risk awareness or information need) in each model, to determine mediating effects. Comparison of model 1 and 2 revealed that information need is a more powerful predictor of the level of preparedness than risk awareness. Excluding risk awareness from the analysis only slightly reduced the explained variance. How respondents evaluated the cost benefits of protection measures affected their preparedness: less belief that investments in protective measures were worth the effort resulted in less intent to implement such measures. In contrast, the respondents' belief in the effectiveness of particular measures to prevent flood damage had no explanatory power.

Table 4 shows the results of a regression analysis of the current state of preparedness (already implemented measures) with flood preparedness (the intention to act). The main factors that influenced the respondents' decisions were the evaluation of cost benefits, followed by a low level of acceptance of the risk of being evacuated. The third strongest predictor was the respondents' self-assessed level of knowledge before the campaign ${ }^{4}$. Those who reported being well informed had implemented more protective measures than others. In particular, respondents who had been professionally or voluntarily involved in dealing with natural hazards were more likely to have implemented measures. The length of time that property owners' had lived there had some influence, but less than other predictors. Furthermore, respondents' general risk aversion was significantly correlated with their preparedness but risk awareness was not a significant factor (stand. $\beta: 0.043, p=0.423$ ) and adding it to the regression model did not increase the explanatory power of the

\footnotetext{
${ }^{4}$ Question wording: "How would you assess the knowledge about flood risk before the information campaign?"
} 
Table 5. Regression on two major predictors of preparedness (awareness \& evaluation), and the major predictor of awareness (intensity of studying the material).

\begin{tabular}{|c|c|c|c|}
\hline Dependent variable & $\begin{array}{l}\text { Risk } \\
\text { awareness }\end{array}$ & $\begin{array}{l}\text { Evaluation of } \\
\text { the material }\end{array}$ & $\begin{array}{l}\text { Intensity of } \\
\text { studying } \\
\text { the material }\end{array}$ \\
\hline Model summary: & $\begin{array}{l}R^{2}=0.490 \\
F(9,340)=38.325 \\
p<0.000\end{array}$ & $\begin{array}{l}R^{2}=0.3414 \\
F(6,320)=27.575 \\
p<0.000\end{array}$ & $\begin{array}{l}R^{2}=0.475, \\
F(6,274)=43.162, \\
p<0.000\end{array}$ \\
\hline Independent variables & Stand. $\beta$ (SE) & Stand. $\beta$ (SE) & Stand. $\beta$ (SE) \\
\hline Risk awareness & - & $0.238 *(0.066)$ & $0.303 *(0.065)$ \\
\hline Trust in authorities & - & $0.369 *(0.042)$ & $\begin{array}{l}-0.081(0.048) \\
p=0.070\end{array}$ \\
\hline Prior knowledge & $0.207 *(0.030)$ & - & $0.339 *(0.041)$ \\
\hline Intensity of studying & $0.310 *(0.033)$ & $0.156 * * *(0.052)$ & - \\
\hline Risk preparedness & $0.183 *(0.028)$ & $0.157 * *(0.039)$ & - \\
\hline Priority of security & $-0.165 *(0.024)$ & - & - \\
\hline Responsibility politics & $0.119 * *(0.030)$ & - & - \\
\hline Information need & $0.139 *(0.027)$ & - & - \\
\hline Personal experience & $0.132 *(0.046)$ & - & - \\
\hline Opinion that flood risk is generally underestimated & $0.132 *(0.034)$ & - & - \\
\hline Attachment to property & $0.089 *(0.022)$ & - & - \\
\hline Knowledge about location in risk zone & - & - & $0.245 * * *(0.035)$ \\
\hline Talked about the topic of flood to others & - & $0.111 * * *(0.061)$ & - \\
\hline Self-responsibility of owners & - & $0.089 * * *(0.031)$ & $0.127 *(0.034)$ \\
\hline Preference for information letter as means of communication & - & - & $0.153 *(0.032)$ \\
\hline
\end{tabular}

Notes: *** $p<0.001 ; * * p<0.010 ; * p<0.050$.

model. Apart from respondents' cost-benefit evaluations, no predictor correlated with both respondents' intention to prepare and their current state of preparedness.

Preparedness can be interpreted as a predictor of awareness as well, but the direction of the positive relationship between these variables cannot be clarified by this crosssectional study. With Table 5, we provide a more detailed overview of the main predictors of risk preparedness. The results show that trust in authorities not only influences the evaluation of the material, but it also has an effect on the intensity of studying it. The most important predictor for this variable, however, was the level of knowledge the respondents had before they received the letters. Furthermore, intensive study of the campaign material had a significant effect on the respondents' correct indication of their properties' location in a risk zone and a preference for information letters as a means of communication makes it more likely that the material is studied intensively. Level of trust in authorities and feeling of self-responsibility were found to be related to a positive evaluation of the information material, but the data do not indicate whether self-responsibility is a precondition of a positive evaluation, or whether respondents who perceived the material positively develop a feeling of responsibility.

\section{Discussion}

An information campaign, such as the one conducted in Zurich, that distributed written risk information to affected property owners and referred to the city's flood hazard map is representative of probably the most common form of distributing risk information. We evaluated this campaign using a standardized survey to assess its contribution to better risk awareness and risk preparedness of the wider public. Since we could only conduct a cross-sectional survey without a control group, our approach was to compare different groups of respondents. Our results indicate evidence that such a written information campaign can generally increase awareness and preparedness, but only to a limited degree. Therefore, we emphasize the need to further explore the potential role of hazard maps as a means of dialogue-based strategies.

\subsection{Effects of risk communication on flood risk preparedness}

We identified three major effects of the risk communication campaign in the City of Zurich. (1) It increased property owners' intention to implement flood protection measures, (2) it increased their risk awareness, and (3) the adoption of the information provided was closely related to a positive evaluation of the communication campaign. The cam- 
paign was well received by a considerable number of property owners in the areas at risk and significantly influenced their intention to prepare for a flood event. According to our regression analysis, many of the respondents were motivated by the campaign to implement protection measures. This motivating effect was strongly related to a positive evaluation of the communication campaign. A second important predictor of the intention to prepare for a flood event is risk awareness, which was especially high among respondents with high information needs and those who reported having intensively studied the material. It suggests that risk awareness can be shaped by appropriate risk communication. The results showed that the respondents have a rather positive attitude towards risks, and a common comment on the questionnaire was "Risk is a part of life". It would be worth keeping this positive attitude that people may have towards taking risks in mind when designing a communication strategy.

Interestingly, we found risk awareness, information needs, (subjective) knowledge, the intensity of studying the material and the readiness to use different media to gather further information to be strongly inter-related. It is difficult to interpret the causal direction of these correlations, but they confirm that the campaign not only directly increased flood risk preparedness, but also improved the conditions under which such information is likely to be recognized and adopted by the public in future. A new empirical finding is that the respondents who read the information material more intensively are correspondingly more motivated to apply individual prevention measures. In contrast, the amount of time they spent studying the information material had no positive effect on their intention to prepare for a flood. The same correlation pattern was found for risk awareness. In support of the findings of Griffin et al. (2004), we conclude that making citizens aware of the availability of information is basic to risk communication but the openness of different population groups to different kinds of media needs to be considered. Our study clearly showed that elderly people prefer written forms of information.

In line with findings of other studies (Demeritt et al., 2011; Löfstedt and Perri, 2008; Terpstra and Guttelin, 2008), we found items related to political culture to be relevant, and an important condition affecting the effectiveness of risk communication is trust in the distributers of the information material. Our results show that trust in particular affects risk communication by shaping the perception and evaluation of the information material. The agencies responsible for risk communication need to take into consideration how they are perceived by the public, and how important it is to gain trust in their risk management. As Veland and Aven (2013) point out, gaining the trust of laypeople is crucially related to the communication of uncertainties, however, building up trust is rather complex and requires further research attention.

Our data allow us to distinguish to a certain extent between the influence of individual characteristics, such as personal risk aversion, and the effect of the campaign on the respondents' risk preparedness. Although there is a significant positive relationship between risk aversion and flood preparedness, risk aversion was not a significant predictor of preparedness in the regression model and the influence of this individual characteristic is marginal compared to the influence of other variables. Addressing our second research question on other factors that influence the level of preparedness, our results show that some predictors of people's readiness to implement protection measures in the future were not related to the campaign. Risk preparedness is also a matter of individual characteristics and preferences. Prioritizing the value of safety over that of avoiding public debt and regulations represents a personal attitude that did not correlate with any variables related to the campaign. This is surprising since it actually had influence on preparedness. It therefore appears to be not readily influenced by risk communication.

Similarly, general risk aversion increased people's readiness to adopt safety measures. Unlike in several previous studies (Siegrist and Gutscher, 2006; Grothmann and Reusswig, 2006; Lindell and Hwang, 2008), we found no direct influence of personal flood experience on risk preparedness. Experience had no significant effect on either the intention to implement protective measures or the current state of preparedness. However, personal flood experience resulted in increased risk awareness. We assume that the effect of such an experience diminishes with time and hence had little relevance for those living in Zurich. The last severe flood in Zurich occurred in 1910, so we cannot assume that anyone in the sample remembers this event. Of course, personal flood experience was not necessarily related to this area. In our study, we did not distinguish between whether the flood experience was recent or older, nor did we consider the quality of such experience, such as whether the experience was perceived negatively or whether it had strengthened the person's feeling of self-efficacy. These aspects remain open for future research.

The distinction between the intention to take protective actions and the actual level of preparedness helps to explain the rather contradictory findings of other studies about the influence of gender on risk preparedness (Grothmann and Reusswig, 2006; Miceli et al., 2008). This gender difference in flood risk preparedness is, to some extent, due to the influence of gender on worry. Since worry was found to be an important predictor of risk awareness, the gender effect may be explained by this influence. The results of these studies show no clear pattern of the influence of gender on risk preparedness, although they measured preparedness in various ways; sometimes as the intention or readiness to prepare for hazards and sometimes as actually implemented measures. Age had no significant effect on property owners' risk preparedness, but those with higher education tended to be slightly better prepared. However, no negative effect was measured among less educated respondents. Age had some influence on risk awareness, but not on preparedness. The finding that age was negatively correlated with the strength of opinion 
that floods are of personal relevance may be explained in that one item of the relevance scale represented the perceived probability of experiencing a severe flood in one's lifetime, and that older people may perceive a smaller window of opportunity. A more interesting predictor is professional background, as those with previous involvement in recovery activities as a professional or volunteer were usually well prepared. In contrast to respondents who had no such background, they were significantly more critical towards the authorities in their judgement of public risk management. Involvement in hazard management therefore seems to influence self-responsibility and critical reflection of public risk management. Overall, experience of active involvement in recovery activities seems to be more important than having personally experienced flood damage. Finally, those owners who had already planned to reconstruct their property were mostly willing to consider flood prevention measures. This indicates that effective risk communication should especially address property owners planning to build on their property.

\subsection{Raising awareness, knowledge and information behaviour}

A key finding is that the effective communication of hazard maps or other tools of risk prevention is still a challenge when implementing integrated risk management, as it relies on the involvement of all responsible actors, including the owners of properties in risk areas. Unless they are aware of the risks they are exposed to and are informed about protection measures, only a small minority of them can be motivated to gather further information and to prepare for a flood event. Although the campaign had a measurable influence on public awareness and preparedness, our results revealed that the impact is still rather low. This indicates that a single campaign does not convey enough risk information and a campaign that raises awareness over a longer period of time is required. Ongoing provision of information appears to be a fruitful basis for future risk communication. Our results show that, with a certain level of risk awareness and knowledge about floods, people are more likely to notice the information in the first place. Findings of other studies, however, indicate that the relationship between awareness and preparedness is ambiguous (Scolobig et al., 2012) and empirical findings do not support the conclusion that a linear relationship can be generally assumed. Our results clearly showed that awareness strongly influences property owners' intentions to act, but there is no evidence that awareness results in actual protective behaviour. Hence, the mediating effect of other variables and context factors needs to be examined further to better understand how raising awareness contributes to flood preparedness.

We also examined several variables related to awareness, including knowledge and information behaviour. Factual knowledge about flood risk areas was strikingly deficient, but did not seem to be relevant for the respondents in decid- ing whether to take protective actions. In contrast, subjective knowledge was important as a predictor of whether respondents had already adopted measures. Most respondents had not conducted protection measures yet. Among those who did, the most frequent measure was "install building floodproof equipment" (adopted by $11.1 \%$ ). Short-term measures were only implemented by an even smaller proportion of respondents: "inform tenants" (6.1\%), "temporary measures" (7.4\%), and only $2.0 \%$ had worked out an emergency plan. Furthermore, the more self-assessed knowledge a respondent reported, the more interest they took in the topic of flood and the more they wanted further information. This finding shows how risk communication encouraged property owners' to seek information as it was clearly in their interest.

Factual knowledge about risk areas was found to be distinct from risk awareness, which was more a matter of interest (relevance), perceived probability of severe flood damage and worry about such damage. We therefore recommend considering these items as distinct dimensions of risk awareness in studies on risk preparedness and communication. We support the view that effective risk communication involves more than merely transferring expert knowledge to laypeople. It should also address emotions and raise the addressees' interest in the topic. As Parker et al. (2009) claims, effective flood communication stimulates the addressees to wonder about their environment and to question their safety in it. Our data confirmed that the campaign motivated almost half of the respondents to talk about the topic in private circles. By talking about flood risks, people act as multipliers in risk communication and potentially motivate others to obtain information about the topic. Our findings showed that risk awareness was higher among respondents who know someone who has been affected by a flood, and it was also higher among those who talked about the topic in private. This is important because our findings suggest that raising awareness begins by stimulating information needs, such as by making property owners or residents take interest in the topic and realize that they live in a flood-prone area. Therefore we suggest that future research should focus on the dynamics of information sufficiency (Kellens et al., 2012; Paton et al., 2001). Our results confirm a positive relationship between information seeking and the intention to prepare for a flood. But, unlike Kellens et al. (2012), we found that respondents with strong information needs put more effort into information seeking (studying the material intensively) and were less reluctant to use different means of communication (such as newspapers, TV, and internet). Long-term residents, in particular, reported more intensive informationseeking behaviour and a higher level of self-assessed knowledge about flood risks. This was also confirmed by a qualitative study on risk awareness among property owners in the UK (Burningham et al., 2008).

Another relevant aspect of information processing is, according to Griffin et al. (2004), the role of emotions towards managing agencies. They found that, apart from individual 
risk awareness, anger and a low level of trust in authorities increased active information seeking. In our study, respondents seemed to have high levels of trust in public flood risk management, which had a positive effect on the perception of the official information material. On the other hand, high trust in authorities did not make the respondents more open to gaining additional information from other sources. It should be noted that not only the authorities, but also insurance companies are relevant players in risk communication and attitudes toward such companies should also be taken into account in future research on risk communication (Botzen et al., 2009b).

Further, our results show that attitudes towards responsibility need to be considered in research as well as for risk management strategies. We found that respondents who ascribed the main responsibility to the authorities tended to accept fewer risks, and respondents with a strong feeling of self-responsibility were more willing to accept risks. In contrast to Bicherd and Kazmierczak (2012), our results show that self-responsibility was not contrary to responsibility attributed to the authorities. The respondents rather tended to perceive responsibility as shared between all actors involved in flood protection. This indicates a certain openness towards the idea of integrated risk management. However, more research is required to understand whether risk communication can affect the feeling of self-responsibility, or to what extent it is rather a matter of trust in authorities and other cultural factors.

\subsection{Limitations}

With our study, we aim to provide empirical evidence on the influence a one-way information campaign can influence property owners' risk awareness and preparedness. Although it was not possible to validate our results by a research design including a control group, we argue to consider the results of our evaluation as valid. The effect could be measured in terms of how intensively the property owners read the information material. In particular, there appeared to be significant differences between respondents who read the material more intensively than those who read it less intensively in terms of their risk awareness (see Table 5). We then examined a possible covariate problem, i.e. if preparedness and intensity of studying the information were dependent on the same variables. Our regression analysis, however, clearly showed that preparedness and intensity of studying the information are mainly influenced by different variables (see Table 5). So, in our view, intensity of studying the information is an independent influence factor of preparedness, and group differences of this variable can be used as a proxy to measure the effect of the information campaign. Naturally there are limitations in particular in terms of the conclusions: we cannot make statements about the full effect of the information campaign, but we can provide evidence that if the target group reads the information more intensively, the effect is significantly stronger.
There are a number of findings that confirm the moderate effect of the information campaign as additional indication.

Firstly, about $15 \%$ of the respondents reported that the campaign had motivated them to implement protection measures. This result corresponds with the result of our regression on risk preparedness, in which the evaluation of the campaign explained $19 \%$ of the variance of preparedness. Furthermore, we found significant differences in the level of preparedness between respondents who evaluated the material positively, and those who evaluated it more negatively.

As for the effect on property owners' knowledge about flood risk, only $15 \%$ of the respondents assessed their knowledge before the information campaign as high or rather high, and more than $60 \%$ of the respondents expressed that the campaign improved their knowledge about flood risks.

\section{Conclusion and recommendation for risk communication practice}

With this study, we aimed to provide a detailed analysis of influences on awareness and preparedness, and the role of one-way communication as a means of strengthening these social capacities in flood risk management. We contribute to the discussion on risk communication by providing methodological transparency (an overview of all items used in the questionnaire is included as well as scale construction based on these single items), and by providing insights on the interconnectedness between individual attitudes and the particular context of our research area. This allows the reader to critically interpret our results and it might inspire future research.

The study is not without limitations. The $34 \%$ response rate is high but does not provide reliable information about risk awareness and the level of preparedness in the whole population. It can be assumed that those who did not return the questionnaire are less interested in the topic. Those who answered the questionnaire probably were more concerned about flood risks than those who responded only after receiving a reminder $(F(1, n=460)=4.919, p<.05)$. Our results may therefore be slightly biased towards an overestimation of risk awareness and the intention to adopt protection measures. Since all property owners in areas at risk (and no others) received the information material, no control group could be established. In the research design we considered this shortcoming and addressed it by comparing different groups of respondents: those who read/used the material, and those who did not, i.e. these respondents were not exposed to the stimulus. However, the group of non-users cannot be treated as a control group, because of the issue of self-selection to participate in the survey.

Despite these limitations, the study contributes to a better understanding of property owners' willingness to implement preventive protection measures, and shows that their decisions can be influenced through risk communication. However, the efficacy of information campaigns is limited by cer- 
tain context factors and underlying indirect factors also influence the effects of risk communication. For example, the way respondents evaluated the campaign turned out to be crucial. The positive evaluation of the information material itself was mainly shaped by the property owners' trust in the authorities who distributed the material.

This result shows that the way authorities act towards the citizens is an investment in their credibility and the effectiveness of future communication campaigns. Furthermore, it shows once again that information needs to be tailored to the information needs of addressees in terms of their preferred communication channels and content. It is important to connect information with what people already know to ensure they pay attention to it. Their knowledge and interests vary according to age, gender, previous hazard experience and other factors, so the designers of risk communication need to be aware of the information needs of the target population and the best means of communication. Elderly people in our study were less likely to access online information, and few respondents accessed the online hazard map to check the location of their property in the risk area.
The effect of a single one-way communication campaign was found to be limited, which allows the conclusion that information should be distributed regularly and different target groups should be specifically addressed with regard to the content and the means of communication. We also recommend providing detailed information on the benefits of different protection measures and the efforts required to implement them, and to consider hazard maps as a means of two-way communication. Hazard maps make it evident to property owners that they are faced with hazard risks which motivates them to bring up the topic and raises a communication need. This can be used as a basis of dialogue-based strategies in risk management. Any effort taken to anchor flood risks in the public mind can be a step towards reducing future flood damage and increasing the chances that new information will be noticed. Awareness of flood risks strongly relies on media and campaigns that attract public attention, especially in areas where flood danger is a topic issue. 


\section{Appendix A}

Table A1. Single items in the questionnaire (not used for scale construction).

\begin{tabular}{|c|c|c|c|c|}
\hline Items & $N$ & $M^{\mathbf{a}}$ & SD & Range \\
\hline Perceived fire risk of fire to own property & 491 & 2.02 & 0.837 & $0-5$ \\
\hline Perceived risk of industrial accidents in the City of Zurich & 491 & 2.01 & 0.794 & $0-5$ \\
\hline Perception of public discourse: underestimation of risks & & & & \\
\hline (industrial accident, nuclear energy, ozone in air) & 471 & 3.29 & 0.819 & $1-5$ \\
\hline Self-assessed knowledge about flood risks (feel well informed) & 456 & 3.33 & 1.092 & $1-5$ \\
\hline Self-assessed knowledge about flood risks before the campaign & 487 & 2.60 & 0.995 & $1-5$ \\
\hline Prefer to bear the costs of flood damage than invest in mitigation & 480 & 2.47 & 1.136 & $1-5$ \\
\hline Ability to implement prevention measures & 479 & 2.50 & 1.196 & $1-5$ \\
\hline Perceived location in a risk area (red, blue, yellow, yellow-white) & 350 & “don't know” & 1.107 & $0-4$ \\
\hline General risk aversion & 448 & 3.30 & 0.881 & $1-6$ \\
\hline Priority of safety vs. green spaces & 465 & 2.87 & 1.279 & $1-5$ \\
\hline Perceived responsibility of insurance companies & 401 & 4.1 & 1.371 & $1-6$ \\
\hline Read printed information material & 480 & 0.73 & 0.444 & $0-1$ \\
\hline Accessed online hazard map & 485 & 0.31 & 0.461 & $0-1$ \\
\hline Average time taken to study print material (minutes) & 491 & 11.44 & 16.809 & $0-210$ \\
\hline Average time taken to study online hazard map (minutes) & 492 & 4.87 & 16.336 & $0-300$ \\
\hline Intensity of studying the material & 483 & 1.43 & 0.975 & $0-4$ \\
\hline Information need & 477 & 2.77 & 1.064 & $1-5$ \\
\hline Preference for information sources (media) other than information letters & 30 & 2.6556 & 0.97176 & $1-5$ \\
\hline Talked about the topic in private circles & 460 & 0.41 & 0.493 & $0-1$ (no-yes) \\
\hline Talked about the topic to experts & 460 & 0.08 & 0.276 & $0-1$ (no-yes) \\
\hline Number of flats owned & 489 & 6.57 & 36.899 & $0-600^{\mathrm{b}}$ \\
\hline Number of houses owned & 264 & 2.16 & 4.498 & $0-50$ \\
\hline Number of offices owned & 92 & 3.26 & 7.785 & $0-50$ \\
\hline Live in own property & 491 & 0.66 & 0.474 & $0-1$ \\
\hline Gender & 477 & 1.65 & 0.478 & $1-2(1=$ female, $2=$ male $)$ \\
\hline Number of objects (flats, houses) & 492 & 18.87 & 143 & $0-2091$ \\
\hline Age & 394 & 61.44 & 13.576 & $23-102$ \\
\hline Highest level of education & 451 & University degree (32\%) & 1.32 & $1-5$ \\
\hline Household size & 393 & 2.45 & 1.137 & $1-7$ \\
\hline Have children & 483 & “yes" (75\%) & 0.439 & $0-1$ \\
\hline Number of already implemented measures & 428 & 0.64 & 0.944 & $0-6$ \\
\hline Could imagine selling the property & 456 & 2.05 & 1.284 & $1-5$ \\
\hline Feeling of responsibility for the object & 460 & 4.09 & 1.242 & $1-5$ \\
\hline Floods in the city of Zurich can reliably be predicted & 458 & 3.03 & 1.137 & $1-5$ \\
\hline Flood damage will occur more frequently in future & 488 & 3.46 & 1.165 & $1-5$ \\
\hline $\begin{array}{l}\text { The printed information material motivates me } \\
\text { to take precautionary measures }\end{array}$ & 368 & 2.31 & 1.158 & $1-5$ \\
\hline
\end{tabular}

Notes: ${ }^{a}$ For the categorical variables, the median category is given instead of the mean value. ${ }^{b}$ Apart from private property owners, the sample included non-private owners like companies or housing associations (number of non-private owners in the sample: $n=48$ ). Private respondents owned 19 objects (houses, flats, office rooms) on average. (Remark: here, the term "private" is not used in contrast to "public" or "governmental", but in contrast to organizations). 
Acknowledgements. The authors thank their colleagues for continuing support and discussion, the officials from the municipality of Zurich for enabling the survey, and the referees for assisting in evaluating this paper. The study was financed in the frame of the EU project KULTURisk. The authors thank the officials from the municipality of Zurich (especially B. Kuhn) for enabling the survey, and D. Aller from the cantonal building insurance for supporting questionnaire design. Further, the authors thank their colleagues for continuing support and discussion, and the reviewers for their constructive criticism in evaluating this paper.

Edited by: B. Merz

Reviewed by: three anonymous referees

\section{References}

Basic, F., Cartwright, W., and Handmer, J.: Geographic Visualization Tools for Communication the Risk of Floods, Department of Geospatial Science, Centre for Risk and Community Safety, RMIT University, Melbourne, 2033-2044, 2009.

Bicherd, E. and Kazmierczak, A.: Are property owners willing to adapt to and mitigate the effects of climate change?, Clim. Change, 112, 633-654, doi:10.1007/s10584-011-0257-8, 2012.

Botzen, W. J. W., Aerts, J. C. J. H., and van den Bergh, J. C. J. M.: Dependence of flood risk perceptions on socioeconomic and objective risk factors, Water Resour. Res., 45, W10440, doi:10.1029/2009WR007743, 2009a.

Botzen, W. J. W., Aerts, J. C. J. H., and van den Bergh, J. C. J. M.: Willingness of property owners to mitigate climate risk through insurance, Ecol. Econ., 68, 2265-2277, doi:10.1016/j.ecolecon.2009.02.019, 2009b.

Bradford, R. A., O’Sullivan, J. J., van der Craats, I. M., Krywkow, J., Rotko, P., Aaltonen, J., Bonaiuto, M., De Dominicis, S., Waylen, K., and Schelfaut, K.: Risk perception - issues for Flood management in Europe, Nat. Hazards Earth Syst. Sci., 12, 2299-2309, doi:10.5194/nhess-12-2299-2012, 2012.

Buchecker, M., Salvini, G., Di Baldassarre, G., Semenzin, E., Maidl, E., and Marcomini, A.: The role of risk perception in making flood risk management more effective, Nat. Hazards Earth Syst. Sci., 13, 3013-3030, doi:10.5194/nhess-13-30132013, 2013.

Birkholz, S., Muro, M., Jeffrey, P., and Smith, H. M. Rethinking the relationship between flood risk perception and flood management, Sci. Total Environ., 478, 12-20, doi:10.1016/j.scitotenv.2014.01.061, 2014.

Bubeck, P., Botzen, W. J. W., and Aerts, J. C. J. H.: A review of risk perceptions and other factors that influence flood mitigation behavior, Risk Anal., 32, 1481-1495, doi:10.1111/j.15396924.2011.01783.x, 2012.

Bubeck, P., Botzen, W. J. W., Kreibich, H., and Aerts, J. C. J. H.: Detailed insights into the influence of flood-coping appraisals on mitigation behaviour, Global Environ. Change, 23, 1327-1338, 2013.

Burningham, K., Fielding, J., and Thrush, D.: "It'll never happen to me": understanding public awareness of local flood risk, Disasters, 32, 216-238, doi:10.1111/j.1467-7717.2007.01036.x, 2008.
Demeritt, D., Nobert, S., and Buchecker, M.: Models of "good" risk communication for flooding and other water-related hazards: a critical review, Report for WP5 of KULTURisk, EN. V.2010.1.3.2-1, available at: http://www.kulturisk.eu/ (last access: 3 December 2013), 2011.

de Moel, H., van Alphen, J., and Aerts, J. C. J. H.: Flood maps in Europe - methods, availability and use, Nat. Hazards Earth Syst. Sci., 9, 289-301, doi:10.5194/nhess-9-289-2009, 2009.

Douglas, M. and Wildavsky, A. B.: Risk and Culture: An Essay on the Selection of Technical and Environmental Dangers, University of California Press, Berkeley, 1982.

Eiser, J. R., Bostrom, A., Burton, I., Johnston, D. M., McClure, J., Paton, D., and van der White, M. P.: Risk interpretation and action: a conceptual framework for responses to natural hazards, Int. J. Disaster Risk Reduc., 1, 5-16, doi:10.1016/j.ijdrr.2012.05.002, 2012.

Fischhoff, B.: Risk perception and communication unplugged: twenty years of process, Risk Anal., 15, 137-45, 1995.

Floyd, D. L., Prentice-Dunn, S., and Rogers, R. W.: A meta-analysis of research on protection motivation theory, J. Appl. Soc. Psychol., 30, 407-429, doi:10.1111/j.15591816.2000.tb02323.x, 2000.

Ge, Y., Xu, W., Gu, Z. H., Zhang, Y. C., and Chen, L.: Risk perception and hazard mitigation in the Yangtze River Delta region, China, Nat. Hazards, 56, 633-648, 2011.

Griffin, R. J., Neuwirth, K., Dunwoody, S., and Giese, J.: Information sufficiency and risk communication, Media Psychol., 6, 23-61, doi:10.1207/s1532785xmep0601_2, 2004.

Grothmann, T. and Reusswig, F.: People at risk of flooding: why some residents take precautionary action while others do not, Nat. Hazards, 38, 101-120, doi:10.1007/s11069-005-8604-6, 2006.

Hagemeier-Klose, M. and Wagner, K.: Evaluation of flood hazard maps in print and web mapping services as information tools in flood risk communication, Nat. Hazards Earth Syst. Sci., 9, 563574, doi:10.5194/nhess-9-563-2009, 2009.

Harries, T.: Why most "at-risk" property owners do not protect their homes from flooding, in: Flood Hazards - Impacts and Responses for the Built Environment, edited by: Lamond, J., Booth, C., Hammond, F., and Proverbs, D., Florida, US, CRC Press, Boca Raton, 327-341, 2012.

Höppner, C., Buchecker, M., and Frick, J.: What drives people's willingness to discuss local landscape development?, Lands. Res., 33, 605-622, doi:10.1080/01426390802013549, 2008.

Höppner, C., Whittle, R., Brundl, M., and Buchecker, M.: Linking social capacities and risk communication in Europe: a gap between theory and practice?, Nat. Hazards, 64, 1753-1778, doi:10.1007/s11069-012-0356-5, 2012.

Junker, B., Buchecker, M., and Müller-Böker, U.: Objectives of public participation: Which actors should be involved in the decision making for river restorations, Water Resour. Res., 43, 1-11, doi:10.1029/2006WR005584, 2007.

Kahan, D. M., Jenkins-Smith, H., and Braman, D.: Cultural cognition of scientific consensus, J. Risk Res., 14, 147-174, doi:10.1080/13669877.2010.511246, 2011.

Kellens, W., Zaalberg, R., and De Maeyer, P.: The Informed Society: An Analysis of the Public's Information-Seeking Behavior Regarding Coastal Flood Risks, Risk Anal., 32, 1369-1381, doi:10.1111/j.1539-6924.2011.01743.x, 2012. 
Kellens, W., Terpstra, T., and De Maeyer, P.: Perception and communication of flood risks: a systematic review of empirical research, Risk Anal., 33, 1-26, doi:10.1111/j.15396924.2012.01844.x, 2013.

Keller, C., Siegrist, M., and Gutscher, H.: The role of the affect and availability heuristics in risk communication, Risk Anal., 26, 631-639, doi:10.1111/j.1539-6924.2006.00773.x, 2006.

Krasovskaia, I., Gottschalk, L., Skiple Ibrekk, A., and Berg, H.: Perception of flood hazard in countries of the North Sea region of Europe, Nord. Hydrol., 38, 387-399, 2007.

Lin, S. Y., Shaw, D. G., and Ho, M. C.: Why are flood and landslide victims less willing to take mitigation measures than the public?, Nat. Hazards, 44, 305-314, 2008.

Lindell, M. K. and Hwang, S. N.: Household's perceived personal risk and responses in a multihazard environment, Risk Anal., 28, 539-556, doi:10.1111/j.1539-6924.2008.01032.x, 2008.

Lindell, M. K. and Perry, R. W.: Household adjustement to earthquake hazard: a review of research, Environ. Behav., 32, 461500, doi:10.1177/00139160021972621, 2000.

Lindell, M. K. and Perry, R. W.: Communicating Environmental Risk in Multiethnic Communities, Sage Publications, Thousand Oaks, CA, doi:10.4135/9781452229188, 2004.

Löfstedt, R. E. and Perri, G.: What environmental and technological risk communication research and health risk research can learn from each other, J. Risk Res., 11, 141-167, doi:10.1080/13669870701797137, 2008.

Martens, T. B. E. and Ramm, K.: Risikoverarbeitung und Risikoverhalten am Beispiel extremer Hochwasserereignisse, Schlussbericht für das Bundesministerium für Bildung und Forschung, University of Bremen, Germany, 2008 (in German).

Martens, T., Garrelts, H., Grunenberg, H., and Lange, H.: Taking the heterogeneity of citizens into account: flood risk communication in coastal cities - a case study of Bremen, Nat. Hazards Earth Syst. Sci., 9, 1931-1940, doi:10.5194/nhess-9-1931-2009, 2009.

Miceli, R., Sotgiu, I., and Settanni, M.: Disaster preparedness and perception of flood risk: a study in an alpine valley in Italy, J. Environ. Psychol., 28, 164-173, 2008.

O’Sullivan, J. J., Bradford, R. A., Bonaiuto, M., De Dominicis, S., Rotko, P., Aaltonen, J., Waylen, K., and Langan, S. J.: Enhancing flood resilience through improved risk communications, Nat. Hazards Earth Syst. Sci., 12, 2271-2282, doi:10.5194/nhess-122271-2012, 2012.

Parker, D. J., Priest, S. J., and Tapsell, S. M.: Understanding and enhancing the public's behavioural response to flood warning information, Meteorol. Appl., 16, 103-114, 2009.

Paton, D., Johnston, D., Smith, L., and Millar, M.: Responding to hazard effects: Promoting resilience and adjustment adoption, Aust. J. Emerg. Manage., 16, 47-52, 2001.

Raaijmakers, R., Krywkow, J. R., and van der Veen, A.: Flood risk perceptions and spatial multi-criteria analysis: an exploratory research for hazard mitigation, Nat. Hazards, 46, 307-322, 2008.

Renn, O.: Risk Governance: Coping with Uncertainty in a Complex World, Earthscan, London, 2008.

Rogers, R. W. and Prentice-Dunn, S.: Protection motivation theory, in: Handbook of Health Behavior Research, edited by: Gochman, D. S., Plenum, New York, 113-132, 1997.
Scolobig, A., De Marchi, B., and Borga, M.: The missing link between flood risk awareness and preparedness: findings from case studies in an Alpine Region, Nat. Hazards, 63, 499-520, doi:10.1007/s11069-012-0161-1, 2012.

Siegrist, M. and Gutscher, H.: Flooding risks: a comparison of lay people's perceptions and expert's assessments in Switzerland, Risk Anal., 26, 971-979, doi:10.1111/j.15396924.2006.00792.x, 2006.

Siegrist, M. and Gutscher, H.: Natural hazards and motivation for mitigation behavior: people cannot predict the affect evoked by a severe flood, Risk Anal., 28, 771-778, doi:10.1111/j.15396924.2008.01049.x, 2008.

Siegrist, M.: The necessity for longitudinal studies in risk perception research, Risk Anal., 33, 50-51, doi:10.1111/j.15396924.2012.01941.x, 2013.

Slovic, P.: Perception of risk, Science, 236, 280-285, doi:10.1126/science.3563507, 1987.

Slovic, P.: The feeling of risk, Earthscan, London, UK, 2010.

Slovic, P., Finucane, M. L., Peters, E., and MacGregor, D. G.: Risk as analysis and risk as feelings: some thoughts about affect, reason, risk, and rationality, Risk Anal., 24, 311-322, doi:10.1111/j.0272-4332.2004.00433.x, 2004.

Takao, K., Motoyoshi, T., Sato, T., and Fukuzono, T.: Factors determining residents' preparedness for floods in modern megalopolises: the case of the Tokai flood disaster in Japan, J. Risk Res., 7-8, 775-787, doi:10.1080/1366987031000075996, 2004.

Terpstra, T.: Emotions, trust, and perceived risk: affective and cognitive routes to flood preparedness behavior, Risk Anal., 31, 1658-1675, doi:10.1111/j.1539-6924.2011.01616.x, 2011.

Terpstra, T. and Guttelin, J. M.: Households' Perceived Responsibilities In Flood Risk Management in The Netherlands, Int. J. Water Resour. D, 24, 555-565, doi:10.1080/07900620801923385, 2008.

Terpstra, T., Gutteling, J. M., Geldof, G. D., and Kappe, L. J.: The perception of flood risk and water nuisance, Water Sci. Technol., 54, 431-439, doi:10.1080/1366987031000075996, 2006.

Terpstra, T., Lindell, M. K., and Gutteling, J. M.: Does communicating (flood) risk affect (flood) risk perceptions? Results of a quasi-experimental study, Risk Anal., 29, 1141-1155, doi:10.1111/j.1539-6924.2009.01252.x, 2009.

Thieken, A. H., Kreibich, H., Muller. M., and Merz, B.: Coping with floods: preparedness, response and recovery of flood-affected residents in Germany in 2002, Hydrolog. Sci. J., 52, 1016-1037, doi:10.1623/hysj.52.5.1016, 2007.

Tobin, G. A.: The Levee love affair: a stormy relationship, Water Resour. Bull., 31, 359-367, 1995.

Veland, H. and Aven, T.: Risk communication in the light of different risk perspectives, Reliabil. Eng. Syst. Safe., 110, 34-40, 2013.

Visschers, V. H. M., Wiedemann, P. M., Gutscher, H., Kurzenhäuser, S., Seidl, R., Jardine, C. G., and Timmermans, D. R. M.: Affect-inducing risk communication: Current knowledge and future directions, J. Risk Res., 15, 257-271, doi:10.1080/13669877.2011.634521, 2012.

Wachinger G., Renn O., Begg C., and Kuhlicke C.: The Risk Perception Paradox - Implications for Governance and Communication of Natural Hazards. Risk Anal., 33, 1049-1065, doi:10.1111/j.1539-6924.2012.01942.x, 2013. 
Wagner, K.: Mental Models of Flash Floods and Landslides, Risk Anal., 27, 671-682, doi:10.1111/j.1539-6924.2007.00916.x, 2007.

Zaalberg, R., Midden, C., Meijnders, A., and McCalley, T.: Prevention, adaptation, and threat denial: flooding experiences in the Netherlands, Risk Anal., 29, 1759-1778, doi:10.1111/j.15396924.2009.01316.x, 2009.
Zwick, M. M. and Renn, O.: Wahrnehmung und Bewertung von Risiken. Ergebnisse des "Risikosurveys Baden-Württemberg 2001", Gemeinsamer Arbeitsbericht der Akademie für Technikfolgenabschätzung und der Universität Stuttgart, Lehrstuhl für Technik- und Umweltsoziologie, Stuttgart, Germany, available at: http://elib.uni-stuttgart.de/opus/volltexte/2013/8137/pdf/ ab202a.pdf, last access: December 2013, 2002 (in German). 